Artigo Original

Original Article

Lívia Sales da Costa ${ }^{1}$

Lília de Medeiros Alcântara²

Rayanne Santos Alves ${ }^{1}$

Ana Maria Cavalcante Lopes ${ }^{3}$

Antonia Oliveira Silva ${ }^{3}$

Lenilde Duarte de Sá ${ }^{3}$

Descritores

Fonoaudiologia

Saúde da família

Prática profissional

Promoção da saúde

Saúde pública

Keywords

Speech language pathology and audiology

Family health

Professional practice

Health promotion

Public health

Endereço para correspondência:

Lívia Sales da Costa

R. Fernando Luiz Henrique dos Santos, 1346/201, Bessa, João Pessoa (PB), Brasil, CEP: 58037-050.

E-mail: liviafonoaudiologa@hotmail.com

Recebido em: 09/07/2012

Aceito em: 10/06/2013

\section{A prática do fonoaudiólogo nos Núcleos de Apoio à Saúde da Família em municípios paraibanos}

\author{
The practice of speech language pathologists at Family \\ Health Support Centers in municipalities of Paraiba
}

\section{RESUMO}

Objetivo: Analisar o discurso do fonoaudiólogo sobre a prática desenvolvida nos Núcleos de Apoio à Saúde da Família (NASF), secundada pelos conceitos de núcleo e campo em Saúde Coletiva. Métodos: A investigação do tipo qualitativa foi realizada entre abril e junho de 2011 com 12 fonoaudiólogos atuantes nos NASF em municípios paraibanos. O material empírico foi produzido por meio de entrevista semidirigida e verificado mediante a análise de discurso de tendência francesa. Resultados: Na atuação dos fonoaudiólogos prevalece o aspecto curativo, representado por ações individuais de reabilitação. As atividades de promoção da saúde estão centradas na educação voltada a mudanças de comportamentos individuais e de grupos específicos, representadas pela realização de palestras e grupos. Constataram-se dificuldades em desenvolver o trabalho em equipe e a interação entre os profissionais da Estratégia Saúde da Família e dos Núcleos de Apoio, dificuldades estas que contrariam as diretrizes do Ministério da Saúde no que se refere à organização dos processos de trabalho. Os sujeitos referem incompreensão sobre o seu trabalho por parte dos gestores e silenciam-se sobre ações intersetoriais e de empoderamento da população. Conclusão: O trabalho do fonoaudiólogo no NASF, em municípios paraibanos, se revela numa perspectiva nuclear e, para ser efetivo na perspectiva da Saúde Coletiva, se faz necessária a superação de barreiras para que possa ser caracterizado pela interseção entre núcleo e campo.

\begin{abstract}
Purpose: To analyze the discourse of speech language pathologists regarding the practice developed at Family Health Support Centers (FHSC) based on the concepts of center and field in Collective Health. Methods: A qualitative investigation was conducted between April 2011 and June 2011 with 12 speech language pathologists working at the FHSCs of different municipalities of Paraíba. The empirical material was obtained by means of semi-directed interviews and analyzed through the French Discourse Analysis. Results: Regarding the work of speech language pathologists, the curative perspective prevails, exercised through individual rehabilitation initiatives. Health promotion activities are focused on education and aimed at changing the behavior of individuals and specific groups through lectures and group formation. We verified difficulties to develop teamwork and problems of interaction among the professionals at the various FHSCs. These difficulties disregard the guidelines of the Ministry of Health in relation to the organization of work processes. The participants charged the managers with lack of knowledge about their jobs and remained silent about intersectoral actions and the empowerment of the population, which are consistent with the modern concept of health promotion. Conclusion: The work of speech language pathologists at FHSCs in the municipalities of Paraíba has been revealed from a nuclear perspective. In order for it to be effective from the perspective of Collective Health, the barriers that prevent the intersection between center and field must be analyzed.
\end{abstract}

Trabalho realizado no Programa de Pós-Graduação em Enfermagem, Universidade Federal da Paraíba - UFPB João Pessoa (PB), Brasil.

(1) Programa de Pós-Graduação em Enfermagem, Universidade Federal da Paraíba - UFPB- João Pessoa (PB), Brasil.

(2) Programa Institucional de Iniciação Científica (PIBIC), Universidade Federal da Paraíba - UFPB João Pessoa (PB), Brasil.

(3) Departamento de Enfermagem de Saúde Pública e Psiquiatria, Universidade Federal da Paraíba - UFPB João Pessoa (PB), Brasil.

Conflito de interesses: nada a declarar. 


\section{INTRODUÇÃO}

A fonoaudiologia detém-se ao estudo dos aspectos relacionados à comunicação humana, que envolve linguagem, motricidade orofacial, audição e voz. Inserida no campo das ciências da saúde, estabelece parcerias com várias disciplinas, inclusive com as ligadas à saúde comunitária ${ }^{(1)}$. Nas últimas décadas, o fonoaudiólogo vem transpondo barreiras na tentativa de ter reconhecida a sua atuação profissional na rede de serviços de saúde no país, garantindo a sua integração ao campo da Saúde Coletiva.

Saúde Coletiva é compreendida como a determinação histórica de um processo partilhado de produção dos estados de saúde-doença ${ }^{(2)}$. Segundo Breilh, enquanto a saúde pública assume a possibilidade da consecução de melhorias graduais, a Saúde Coletiva propõe a necessidade de uma ação para a mudança radical ${ }^{(2)}$. Movida pela concepção materialista e dialética, ela se coloca como recurso de luta popular que supera o plano fenomênico e individualizado da causação etiológica, ou seja, atuar em Saúde Coletiva significa desenvolver uma prática que se efetive para além da doença — ou da necessidade em si que o usuário apresente - e para além da formação específica do profissional.

Com o surgimento dos Núcleos de Apoio à Saúde da Família (NASF), observa-se que o fonoaudiólogo tem sido requisitado a integrar equipes de apoio à estratégia de saúde da família (ESF), vertente da Atenção Primária à Saúde (APS) no Brasil e reconhecida como principal porta de entrada no sistema de saúde.

O NASF foi criado para apoiar a inserção da ESF na rede de serviços e ampliar a abrangência, a resolutividade, a territorialização e a regionalização, bem como as ações da APS $^{(3)}$. Como integrante do NASF, o fonoaudiólogo se depara com a possibilidade de não apenas atuar no nível do núcleo, mas ir além das ações centradas na clínica individual, restrita ao consultório ou ao espaço da pessoa que demanda os seus serviços, cuja maior expectativa é a reabilitação de funções alteradas em consequência de processos mórbidos ou congênitos. No tocante à Saúde Coletiva, a inserção do fonoaudiólogo conduz a uma prática desenvolvida tanto na perspectiva de núcleo quanto de campo.

Â luz de conceitos elaborados por Campos ${ }^{(4)}$ sobre núcleo e campo em Saúde Coletiva, quando o fonoaudiólogo desenvolve sua prática do ponto de vista clínico e individual, atua na perspectiva de núcleo. Por outro lado, a realização de ações pautadas na insterdisciplinaridade e na multiprofissionalidade diz respeito à sua prática ampliada, na perspectiva de campo.

Nesse sentido, enquanto o núcleo demarcaria a identidade de uma área de saber e práticas, o campo seria um espaço de limites imprecisos onde cada disciplina buscaria outros apoios para cumprir suas tarefas teóricas e práticas ${ }^{(4)}$. No entanto, campo e núcleo não seriam unidades independentes, uma vez que tanto um quanto outro se interinfluenciariam, não sendo possível detectar limites precisos entre eles ${ }^{(4)}$. Ou seja, ao desenvolver ações de promoção da saúde em equipe multidisciplinar, o fonoaudiólogo atuaria na perspectiva de núcleo e de campo.
Convém ressaltar que a demanda pela formação de profissionais em Saúde Coletiva requer do fonoaudiólogo, como trabalhador de saúde, uma atuação além do seu núcleo de saber, de modo que o exercício da prática revele ações de cunho generalista, desenvolvido segundo uma rede de cuidados progressivos ${ }^{(5)}$, relacionando outros saberes e na perspectiva da integralidade em saúde. Nesse sentido, a formação do fonoaudiólogo deve desenvolver competências para a prática exercida desde a atenção básica até a gestão ${ }^{(6)}$. No que concerne à atenção básica, esta pode ser compreendida como um conjunto de ações de caráter individual ou coletivo, voltadas para a promoção da saúde, a prevenção de agravos, o tratamento e a reabilitação ${ }^{(7)}$.

No campo da Saúde Coletiva, a prática do fonoaudiólogo está embasada no conceito moderno de promoção da saúde ${ }^{(8)}$, relacionado ao papel protagônico dos determinantes gerais sobre as condições de saúde. Esse conceito se sustenta na constatação de que a saúde é produto de um amplo espectro de fatores relacionados à qualidade de $v i^{(9)}{ }^{(9)}$ o que inclui padrões adequados de nutrição, habitação, saneamento, condições dignas de trabalho e renda, entre outros, ou seja, que retrata o conceito ampliado de saúde. Logo, o fonoaudiólogo se defronta com o desafio de desenvolver práticas destinadas à coletividade no contexto do Sistema Único de Saúde (SUS), uma vez que esta envolve conhecimentos sobre as condições de saúde e atenção às necessidades da população, segundo a concepção da determinação social da saúde.

Se considerarmos a discreta aproximação histórica da Fonoaudiologia com o contexto intrincado da rede de saúde e das políticas públicas no país ${ }^{(10)}$, o fonoaudiólogo, de forma a superar a reprodução exclusiva do modelo pautado nos atendimentos à demanda espontânea e terapêutica reabilitadoras ${ }^{(10)}$, deve vincular, também os cuidados coletivos no que tange aos aspectos da comunicação humana.

Diante do reconhecimento que a Saúde Coletiva é um saber constitutivo e essencial às práticas em saúde, é fundamental admitir que nela se produzem conhecimentos, políticas e valores relevantes, a partir de outros campos que complementem a atenção, como o da clínica e o da reabilitação(4). Estas práticas, quando exercidas no âmbito da saúde coletiva, devem ainda comtemplar ações destinadas à prevenção das doenças e agravos, produzindo um cuidado integral, o que, para Mattos ${ }^{(11)}$ sugere a horizontalização do cuidado, de forma a superar a fragmentação das ações no interior das unidades de saúde, visto que a integralidade deva ser concebida como conjunto articulado de ações e serviços preventivos e curativos, além de individuais e coletivos, articulado ao moderno conceito de promoção da saúde.

Considerando a atuação do fonoaudiólogo no NASF, questiona-se: como se caracteriza o seu discurso quanto à prática desenvolvida? Segundo a concepção de núcleo e campo, estaria esse profissional no NASF desenvolvendo uma prática sob a perspectiva da Saúde Coletiva? Com o propósito de responder aos questionamentos, o objetivo deste estudo foi analisar o discurso do fonoaudiólogo sobre a prática desenvolvida em equipes NASF, secundada pelos conceitos de núcleo e campo em Saúde Coletiva. 


\section{MÉTODOS}

Este artigo resulta do desenvolvimento do projeto de pesquisa "Atuação do fonoaudiólogo nos Núcleos de Apoio à Saúde da Família na Paraíba: tecendo fios entre a Fonoaudiologia e a Saúde Coletiva", submetido ao Conselho de Ética em Pesquisa do Hospital Universitário Lauro Wanderley (HULW), este vinculado à Universidade Federal da Paraíba, instituição de origem. $\mathrm{O}$ projeto em questão foi aprovado conforme o protocolo $\mathrm{n}^{\mathrm{o}}$ 084/2011. Todos os sujeitos, ao consentirem participar do estudo, assinaram o Termo de Consentimento Livre e Esclarecido.

Trata-se de um estudo qualitativo realizado com 12 fonoaudiólogos atuantes em unidades sede das equipes NASF de municípios paraibanos. As informações para a localização dos sujeitos foram obtidas no Sistema de Cadastro Nacional de Estabelecimentos de Saúde (SCNES) entre os meses de abril e junho de 2011. Para a inclusão dos participantes, os municípios deveriam ter registro no SCNES, informação confirmada junto à Secretaria Estadual de Saúde, assim como a existência de fonoaudiólogo nas unidades sede e que estivessem em pleno exercício de suas funções.

Constatou-se que fonoaudiólogos atuavam nas equipes do NASF em 19 municípios paraibanos. Alguns percalços, como desistências em participar da pesquisa e desligamentos, foram determinantes para que o número de sujeitos fosse reduzido a 12 municípios do Estado da Paraíba e, portanto, esta também foi a quantia de pessoas entrevistadas. A identificação dos fragmentos discursivos é pela sigla NASF acrescida de número e letra.

Os sujeitos estão na faixa etária entre 25 e 35 anos. Do total, nove pertenciam ao gênero feminino. Ao ingressar nas equipes NASF, todos apresentavam, no mínimo, três anos de conclusão do curso de Fonoaudiologia; dois deles possuíam pós-graduação em Saúde Coletiva; outros dois referiram ter recebido capacitação, promovida pela Secretaria Municipal de Saúde, para atuar nas equipes NASF; um revelou não fazer reabilitação, estando suas ações voltadas somente à prevenção; os demais relataram utilizar-se do atendimento individualizado como principal recurso assistencial; todos apontaram dificuldades no compartilhamento das ações com os profissionais da ESF, especialmente médicos e enfermeiros; quatro apontaram incompreensão dos gestores em relação ao seu trabalho, comprometendo a assistência.

O material empírico foi produzido por meio de entrevistas semidirigidas, realizadas no período de abril a junho de 2011, nas quais o pesquisador esteve livre para fazer intervenções e ajustes necessários, que pudessem explorar as colocações do entrevistado ${ }^{(12)}$. Os participantes foram entrevistados por uma pesquisadora fonoaudióloga, e as transcrições tiveram auxílio de uma bolsista do Programa Institucional de Iniciação Científica (PIBIC).

As entrevistas foram submetidas à apreciação de três pesquisadoras do projeto e da orientadora do trabalho de dissertação, do qual este estudo deriva. Dessa forma, conformaram o corpus discursivo, analisado segundo os procedimentos da Análise do Discurso (AD), de matriz francesa e indicada em pesquisas qualitativas pelas possibilidades de relacionamento com os materiais que envolvem valores, juízos necessários e preferíveis como argumentos ou meios capazes de revelar a visão de mundo, sendo, portanto, a posição ideológica do sujeito discursivo ${ }^{(13)}$.

Enunciados, fragmentos e sequências discursivas foram agrupados em duas formações: Formação Discursiva I - A promoção da saúde e a prática do fonoaudiólogo em NASF; e Formação Discursiva II - A relação do fonoaudiólogo com outros profissionais da saúde nas equipes dos NASF.

Nos fragmentos, as partes marcadas se referem às sequências discursivas de referência $(\mathrm{SDR})^{(14)}$, cujos indícios ${ }^{(15)}$ foram verificados pelos autores prescrutados, de maneira a analisar o funcionamento discursivo, ou seja, como o discurso proferido se opera, na intenção de revelar posicionamentos e ideologias dos sujeitos frente às formações discursivas.

\section{RESULTADOS}

No Quadro 1 encontra-se a Formação Discursiva I - A promoção da saúde e a prática do fonoaudiólogo em NASF, conformada por sequências, fragmentos discursivos e SDR.

No Quadro 2 pode ser verificada a Formação Discursiva II - A relação do fonoaudiólogo com outros profissionais da saúde nas equipes dos NASF, também conformada por sequências, fragmentos discursivos e S.D.R.

\section{DISCUSSÃO}

\section{Formação Discursiva I - A promoção da saúde e a prática do fonoaudiólogo em NASF}

A despeito da política nacional de Atenção Básica, que prioriza ações na promoção da saúde e, conforme o Ministério da Saúde, que sugere a presença do fonoaudiólogo entre os demais membros da equipe $\mathrm{NASF}^{(3)}$, percebe-se em um dos fragmentos discursivos, de acordo com as SDR, que a sua ação se encontra centrada no cuidado clínico individualizado. Observa-se que, na interpretação do sujeito, as ações preventivas realizadas no NASF são poucas quando comparadas às ações individuais de reabilitação. Este apontamento sugere uma prática profissional nucleada, que se distancia da perspectiva ampliada do trabalho coletivo, multiprofissional, característica do conceito de campo ${ }^{(4)}$ (Quadro 1, NASF8).

No tocante a essa questão, o Ministério da Saúde afirma que as intervenções diretas, frente a usuários e famílias, podem ser realizadas no NASF, porém sempre sob o encaminhamento das equipes de saúde da família, devendo ocorrer discussões e negociações entre os profissionais responsáveis pelo caso. Tal atendimento, direto e individualizado, deve ocorrer conforme a necessidade ${ }^{(3)}$. Afirma-se que as unidades de saúde ainda têm no modelo médico-assistencial seu principal filão ${ }^{(16)}$, cujo foco reflete na inserção destes profissionais nos serviços, o que concorre para a falta de compreensão do pleno exercício de suas funções.

Para Campos ${ }^{(4)}$, não há limites precisos ou rígidos entre os diferentes modos de produção da saúde. Todos utilizam práticas de promoção e prevenção e ações clínicas de reabilitação e de 
cuidados. Assim, a clínica se vale predominantemente de práticas de atenção ao indivíduo, ainda quando necessite incorporar o social e o subjetivo, operando com algumas práticas de prevenção.

Observa-se que os profissionais se deparam com desafios estruturais que os impelem a agir muito mais em função do aspecto curativo, realçado pela oferta de atendimentos individualizados, o que favorece a hegemonia do modelo biomédico, restringindo, portanto, o cuidado a práticas isoladas de atenção à saúde.

No fio do discurso, constata-se uma evidente contradição: os fonoaudiólogos que atuam nas equipes NASF se posicionam ideologicamente em função de uma prática centrada na prevenção,

Quadro 1. Ações realizadas pelo fonoaudiólogo em equipes de Núcleos de Apoio à Saúde da Família, João Pessoa, 2011

\begin{tabular}{|c|c|}
\hline Sequências discursivas & ragmentos discursivos \\
\hline $\begin{array}{l}\text { O trabalho aqui foge da real proposta do NASF } \\
\text { São realizadas pouquíssimas ações de promoção } \\
\text { e prevenção [...] } \\
\text { com exceção de mais duas manhãs, faço a terapia } \\
\text { individual dos pacientes }\end{array}$ & $\begin{array}{l}\text { O trabalho aqui foge da real proposta do NASF. São realizadas pouquíssimas ações de } \\
\text { promoção e prevenção [...] no que diz respeito apenas ao meu trabalho, realizo visitas/ } \\
\text { atendimentos domiciliares aos pacientes acamados uma manhã por semana e, com } \\
\text { exceção de mais duas manhãs, faço a terapia individual dos pacientes (NASF 8). }\end{array}$ \\
\hline $\begin{array}{l}\text { [...] na promoção da saúde seria onde a gente } \\
\text { deveria mais trabalhar } \\
\text { Trabalhando mais com a promoção, certamente } \\
\text { teríamos uma saúde bem melhor, pois muita coisa } \\
\text { seria prevenida }\end{array}$ & $\begin{array}{l}\text { [...] Então, na promoção da saúde seria onde a gente deveria mais trabalhar para que, } \\
\text { assim, não ocorresse o que está acontecendo. Trabalhando mais com a promoção, } \\
\text { certamente teríamos uma saúde bem melhor, pois muita coisa seria prevenida (NASF 3a) }\end{array}$ \\
\hline $\begin{array}{l}\text { [...] no NASF, segundo o Ministério da Saúde, a gente } \\
\text { trabalha mais com o preventivo para que a população } \\
\text { não chegue a precisar da reabilitação } \\
\text { O próprio quadro de saúde da população faz com que } \\
\text { a gente acabe fazendo mais a reabilitação } \\
\text { Eu faço atendimento individual, quando necessário, por } \\
\text { não haver outro fonoaudiólogo no município } \\
\text { Nos outros quatro que assistimos — pois se trata de } \\
\text { um NASF intermunicipal —-, eu faço mais a parte da } \\
\text { promoção da saúde. Nos outros quatro municípios, faço } \\
\text { o atendimento individualizado quando se faz preciso }\end{array}$ & $\begin{array}{l}\text { Então, no NASF, segundo o Ministério da Saúde, a gente trabalha mais com o preventivo } \\
\text { para que a população não chegue a precisar da reabilitação. Só que o próprio quadro de } \\
\text { saúde da população faz com que a gente acabe fazendo mais a reabilitação (NASF 9). } \\
\text { Eu faço atendimento individual quando necessário por não haver outro fonoaudiólogo } \\
\text { no município [...], mas nos outros quatro que assistimos - pois se trata de um NASF } \\
\text { intermunicipal —, eu faço mais a parte da promoção da saúde. Nos outros quatro } \\
\text { municípios faço o atendimento individualizado quando se faz preciso, porque a gente não } \\
\text { tem muito tempo, pois ficamos viajando pelos outros municípios (NASF 5a). }\end{array}$ \\
\hline $\begin{array}{l}\text { palestras em saúde e grupos com hipertensos, } \\
\text { gestantes, mulheres, adolescentes etc } \\
\text { Eu participo das palestras dos colegas e atuo } \\
\text { junto às ESF }\end{array}$ & $\begin{array}{l}\text { Trabalhamos em creches e escolas e fazermos capacitação com os Agentes Comunitários } \\
\text { de Saúde palestras em saúde e grupos com hipertensos, gestantes, mulheres, } \\
\text { adolescentes etc. (NASF 5c). } \\
\text { Eu participo das palestras dos colegas e atuo junto às ESF nas ações de promoção de } \\
\text { acordo com cada território (NASF 11b) }\end{array}$ \\
\hline
\end{tabular}

Quadro 2. A relação do fonoaudiólogo com outros profissionais da saúde no trabalho das equipes dos Núcleos de Apoio à Saúde da Família, João Pessoa, 2011

\begin{tabular}{|c|c|}
\hline Sequências discursivas & Fragmentos discursivos \\
\hline $\begin{array}{l}\text { profissionais que acham que apenas a sua parte é } \\
\text { o suficiente }\end{array}$ & $\begin{array}{l}\text { Devemos realizar a assistência compartilhada com outros profissionais que acham que } \\
\text { apenas a sua parte é o suficiente (NASF } 3 b \text { ). }\end{array}$ \\
\hline $\begin{array}{l}\text { Mas, às vezes, ele (enfermeiro) também nos barra } \\
\text { e mais do que o médico } \\
\text { Estamos com dificuldades principalmente para ter } \\
\text { acesso aos prontuários dos pacientes para que } \\
\text { facilitemos o acompanhamento }\end{array}$ & $\begin{array}{l}\text { Trabalhamos ainda com o enfermeiro. Mas, às vezes, ele também nos barra e mais do } \\
\text { que o médico. Estamos com dificuldades principalmente para ter acesso aos prontuários } \\
\text { dos pacientes para que facilitemos o acompanhamento (NASF 3c). }\end{array}$ \\
\hline $\begin{array}{l}\text { [...] dificuldades maiores geralmente estão no trato } \\
\text { com os médicos porque sempre estão mudando; } \\
\text { a gente tem mais contato com a Enfermagem }\end{array}$ & $\begin{array}{l}\text { [...] dificuldades maiores geralmente estão no trato com os médicos porque sempre estão } \\
\text { mudando. Então, a gente tem mais contato com a Enfermagem (NASF } 5 \mathrm{~b} \text { ). }\end{array}$ \\
\hline $\begin{array}{l}\text { muitas vezes o gestor não é alguém da saúde, então } \\
\text { ele chega e se depara com coisas que desconhece. } \\
\text { Assim, pode dificultar o nosso trabalho } \\
\text { Para eles (políticos) é mais fácil dar o remédio para curar } \\
\text { são todos profissionais da área de saúde que têm } \\
\text { que passar para a população informações que } \\
\text { favoreçam conhecimentos para o cuidado da saúde } \\
\text { e qualidade de vida }\end{array}$ & $\begin{array}{l}\text { [...] íamos lá mostrar o trabalho porque também muitas vezes o gestor não é alguém da } \\
\text { saúde, então ele chega e se depara com coisas que desconhece. Assim, pode dificultar } \\
\text { o nosso trabalho (NASF 6). } \\
\text { Para eles (políticos) é mais fácil dar o remédio para curar porque envolve o seu nome, } \\
\text { e não prevenir (NASF 3c). } \\
\text { Quanto à promoção da saúde, são todos os profissionais da saúde que têm que passar } \\
\text { para a população informações que favoreçam conhecimentos para o cuidado da saúde } \\
\text { e qualidade de vida (NASF 11a). }\end{array}$ \\
\hline
\end{tabular}


mas desenvolvem, geralmente, ações curativas individualizadas como recurso assistencial único. Em um dos fragmentos discursivos, o fonoaudiólogo interpreta que deveria atuar mais no campo da promoção da saúde. Seu discurso revela, inclusive, que na perspectiva do interdiscurso, a saúde melhoraria, uma vez que muitos agravos poderiam ser prevenidos (Quadro 1, NASF3a).

A atuação do fonoaudiólogo deve envolver o campo clínico e o social, cumprindo um importante papel na rede de cuidados à saúde. Este trabalho requer, necessariamente, equipes interdisciplinares e criação de dispositivos terapêuticos que articulem as ações individuais e coletivas ${ }^{(17)}$, oferecendo apoio matricial, com suporte técnico-pedagógico e, em casos necessários, realizando atuações específicas como prática complementar da atenção.

Como se pode observar, os discursos revelam que é grande a demanda por cuidados e intervenções clínicas assistenciais. É preciso buscar a transformação da prática fonoaudiológica, atualmente centrada em ações individuais e fragmentadas, para um modo de cuidar mais integral e coletivo $^{(18)}$, de modo que supere a prática nuclear do conhecimento, consequente à formação acadêmica recebida (Quadro 1, NASF9). Os sujeitos justificam a pouca atuação preventiva em função do reduzido número de equipes NASF e dos núcleos serem consorciados ou intermunicipais, o que leva o fonoaudiólogo a ter que dar assistência às necessidades de outros municípios, além da demanda do município-sede, implicando no deslocamento constante de uma cidade para outra (Quadro 1, NASF5a).

No que diz respeito à regionalização e à organização dos serviços de saúde, os fonoaudiólogos que atuam nas equipes NASF são, muitas vezes, únicos em relação ao atendimento de uma significativa demanda reprimida, com necessidades diretamente alusivas ao campo da reabilitação, o que dificulta a promoção de práticas preventivas. Nesse sentido, observa-se que as suas ações são localizadas muito mais na perspectiva de núcleo do que na de campo.

Sobre esta questão e a sua relação com o cuidado integral, Mattos $^{(19)}$, ao refletir sobre a integralidade na prática, afirma que a sua primeira dimensão diz respeito à capacidade dos profissionais em responder ao sofrimento manifesto, que resulta na demanda espontânea, de um modo articulado à oferta relativa de ações ou procedimentos preventivos. Assim, o conhecimento sobre as doenças permite aos profissionais de saúde intervirem antes que elas se revelem um sofrimento manifesto, considerando, na perspectiva da integralidade, as recomendações preventivas ${ }^{(19)}$.

Constata-se, enfim, que embora os fonoaudiólogos interpretem que seu papel no NASF deva ser desenvolvido de forma articulada junto às equipes de Saúde da Família e que contemplem, ainda, as ações voltadas à educação em saúde, sua discursividade revela que o trabalho fica reduzido ao aspecto curativo e, portanto, ao conhecimento nucleado, consequente à sua formação e reforçado pela passividade com que ocorrem mudanças relacionadas à reorganização do modelo de atenção em saúde. Esta contradição pode ser compreendida considerando que a área preventivo-comunitária é recente no percurso histórico da Fonoaudiologia e se encontra em processo de conquista de suas especificidades, da construção de sua identidade e caracterização da práxis em Saúde Coletiva ${ }^{(10)}$, articulada ao conceito moderno de promoção da saúde.

\section{Formação Discursiva II - A relação do fonoaudiólogo com outros profissionais da saúde nas equipes dos NASF}

Os discursos revelam que, apesar de os fonoaudiólogos conhecerem a importância do trabalho ser desenvolvido na perspectiva de equipe ${ }^{(20)}$, muitos não o realizam, e que a prática desenvolvida no NASF sofre influências de gestores e integrantes das equipes, em especial, do enfermeiro (Quadro 2, NASF3b). Vestígios revelam que o trabalho é perpassado por supostas relações de poder e pela existência de conflitos entre os membros das equipes NASF e ESF. A falta do médico, dada a sua alta rotatividade nas equipes, contribui para que os fonoaudiólogos tenham mais contato com o enfermeiro, profissional que assume a liderança da equipe e estabelece relação assimétrica de poder com os outros integrantes, o que fragiliza o trabalho do fonoaudiólogo e dificulta a elaboração de um plano de cuidados efetivo.

Foi possível observar dificuldades de interação entre os profissionais da saúde na construção de um processo de trabalho conjunto, tanto entre as equipes NASF quanto entre as equipes NASF e da ESF que, segundo a concepção de campo na Saúde Coletiva, evoca ações pautadas na interdisciplinariedade e na multiprofissionalidade (Quadro 2, NASF5b).

Sobre essas dimensões, o apoio matricial e as equipes de referência são arranjos organizacionais e funcionam como uma metodologia para a gestão do trabalho em saúde, objetivando ampliar as possibilidades de realizar clínica ampliada e integração dialógica entre distintas especialidades e profissões ${ }^{(21)}$.

A composição da equipe de referência e a criação de especialidades em apoio matricial buscam criar possibilidades para se operar com a ampliação do trabalho clínico e do sanitário, já que é considerado que nenhum especialista, de modo isolado, pode assegurar uma abordagem integral ${ }^{(21)}$.

Quanto ao compartilhamento das ações, verificam-se, nos discursos, dois principais pontos. O primeiro diz respeito às disposições do Ministério da Saúde, que, sobre a organização dos processos de trabalho no NASF, recomenda a priorização do atendimento compartilhado e interdisciplinar ${ }^{(3)}$. Dessa forma, o correto entendimento da expressão apoio, central na proposta do NASF, remete à compreensão de um processo de trabalho baseado em equipes de referência. No caso, as equipes da ESF devem receber apoio do NASF para o desenvolvimento de projetos de cuidado focados nas trocas de informações e experiências mútuas, condizentes à noção de campo na Saúde Coletiva ${ }^{(4)}$.

O segundo ponto tem a ver com o não dito no discurso, mas conduz à interpretação de que o sujeito refere que os profissionais da ESF agem com ênfase na especificidade de seu trabalho, conformando uma equipe-ajuntamento, ou seja, trabalham com autonomia plena, dentro do mais amplo espectro de independência de suas ações, fragilizando o trabalho em equipe ${ }^{(20)}$. Essa prática vem impactar a possibilidade da integralidade da atenção, um dos princípios orientadores do $\operatorname{SUS}^{(22)}$, posto que uma prática efetivada na perspectiva de núcleo e campo requer 
a interdisciplinaridade de saberes, estes partilhados e exercidos sob a conformação de uma equipe de saúde.

Em alguns fragmentos discursivos, observa-se que o fonoaudiólogo se vê pressionado a realizar unicamente o atendimento clínico-individualizado, devido à falta de compreensão sobre suas atribuições no NASF, principalmente por parte da gestão municipal. Os sujeitos interpretam que o fato de o gestor não pertencer, muitas vezes, à área da saúde, contribui para que o papel do fonoaudiólogo, na organização e na gestão do cuidado, se distancie das ações preventivas, limitando-se aos atendimentos semelhantes aos desenvolvidos nos ambulatórios de especialidades, onde a prática é exercida principalmente na estrutura de consultório clínico e direcionada ao indivíduo de modo particular (Quadro 2, NASF6; NASF3c). Neste caso, observa-se que a postura dos gestores concorre para que a prática do fonoaudiólogo se realize de forma mais enfática na perspectiva de núcleo.

Os posicionamentos dos sujeitos realçam a importância dos gestores serem esclarecidos sobre as funções do fonoaudiólogo nas equipes NASF, assim como do seu papel no matriciamento, ou seja, servindo de apoio às equipes de referência, de Saúde da Família e na formulação/reformulação e execução de projetos terapêuticos individuais ou coletivos, nos quais há dificuldades em projetá-las, resultando na qualidade do cuidado para com o usuário ${ }^{(22)}$.

As ações de promoção da saúde mais desenvolvidas pelos fonoaudiólogos no âmbito do NASF correspondem às atividades de educação em saúde, que têm a palestra como recurso principal (Quadro 2, NASF5c; NASF11b). Este tipo de técnica ideologicamente se filia ao conceito de promoção da saúde relacionado à transformação de comportamento, distante, portanto, do atual conceito que implica a participação efetiva do sujeito, da comunidade na discussão, elaboração e acompanhamento de planos de saúde ${ }^{(9)}$.

As palestras são comumente descritas como ações de promoção da saúde, idealizadas sob o mesmo conceito de prevenção das doenças (Quadro 2, NASF5c; NASF11b). Ou seja, a partir desta visão, os profissionais de saúde passam a adotar uma prática educativa persuasiva voltada à modificação de padrões comportamentais e não com o objetivo de compreenderem a saúde e a doença em função dos determinantes sociais e da qualidade de vida.

$\mathrm{Na}$ atual política de saúde no Brasil, destacam-se ações específicas de formação de profissionais de saúde articuladas ao desenvolvimento do cuidado no SUS. Neste sentido, faz-se menção a dois aspectos. O primeiro tem relação com a política de Educação Permanente de Saúde (EPS), criada em 2003, na qual a aprendizagem é feita em serviço e em função do quadrilátero que envolve profissionais, gestores, usuários e instituições formadoras ${ }^{(23)}$. O outro está relacionado ao retardo da qualidade das ações de saúde como política pública e empreendida por um estado/município cuidador. No caso, tanto o SUS quanto o processo da reforma sanitária são impactados negativamente por ações pouco alusivas ao conceito moderno de promoção da saúde e ao trabalho em Saúde Coletiva, esta pensada pela sobreposição de campo e núcleo.

Percebe-se que a atuação do fonoaudiólogo no NASF gera cada vez mais necessidades de desenvolver tecnologias de trabalho que possam suprir vulnerabilidades sociais por meio do desenvolvimento de ações de promoção da saúde, condizentes com interseção dos conceitos de campo e núcleo. A interpretação deve nortear o desenvolvimento de um processo de trabalho amplo do fonoaudiólogo na Saúde da Família. Dentre as ações de promoção da saúde, o trabalho com grupos contribui de modo efetivo para a melhoria das condições de vida da população, por meio de cuidados de sujeitos e grupos sociais $^{(24)}$ que antes não tinham acesso ao fonoaudiólogo, nem tais demandas estavam equacionadas de modo minimamente satisfatório no sistema de saúde brasileiro.

A respeito da formação de grupos, o trabalho do fonoaudiólogo inicialmente se restringia a terapias, muitas vezes em decorrência da angústia desses profissionais em reduzir filas de espera ${ }^{(16)}$. Alguns autores ${ }^{(25)}$ comentam que o trabalho com grupos em Fonoaudiologia promove espaços importantes na construção conjunta de conhecimentos e trocas de experiências. Se bem utilizada, essa estratégia pode ampliar o atendimento, dependendo do modo e do contexto em que é empregada ${ }^{(25)}$ (Quadro 2, NASF5). Nesse estudo, a formação dos grupos no NASF é realizada em conjunto com os outros profissionais da equipe, mesmo que a temática seja por vezes específica, o que pode ser considerado um ponto positivo para a integração das ações.

Na relação entre saber e prática no campo da Saúde Coletiva, convém discutir a formação do profissional de saúde como atorsujeito. Sendo o fonoaudiólogo um recente profissional a integrar o campo da Saúde Coletiva, é importante considerar que, na medida em que um determinado contexto favoreça a instalação de novas relações técnicas e sociais sob as quais é realizado o trabalho desses sujeitos-agentes, cabe, então, repensar a formação de novos sujeitos-agentes ${ }^{(26)}$, de modo que atenda às necessidades da coletividade.

No que se refere à formação desses profissionais para a prática em Saúde Coletiva, as universidades têm buscado se adequar a este campo de atuação, reorganizando seus currículos para que os profissionais possam atuar na promoção da saúde e considerando que o trabalho do fonoaudiólogo, até pouco tempo, encontrava-se restrito às atuações na média e alta complexidade ${ }^{(27)}$.

A respeito do conceito de promoção da saúde, os discursos silenciam sobre a participação da população na formulação de políticas e práticas de saúde, exercício de controle social por meio da participação em conselhos locais de saúde, por exemplo. São silentes, ainda, quanto à abordagem intersetorial, uma vez que para a consecução de ações promotoras de saúde, o princípio da intersetorialidade desempenha papel fundamental ${ }^{(28)}$.

Para uma prática efetiva de trabalho de apoio às ESF na atual conjuntura de saúde e sob a concepção da Saúde Coletiva, o processo de trabalho do fonoaudiólogo deve ser operado segundo a perspectiva conjunta de núcleo e campo, de modo que esse insira em seu discurso a promoção da saúde, em que profissional e usuários sejam sujeitos de conquistas e transformações, focadas na saúde como direito e dever de um Estado cuidador.

\section{CONCLUSÃO}

O auxílio da AD como ferramenta de análise para a caracterização da discursividade dos participantes permitiu evidenciar a sua posição em relação ao trabalho em Saúde Coletiva, assim como a filiação ideológica de ações desenvolvidas no NASF, segundo os conceitos de campo e núcleo. 
Os fragmentos discursivos e as SDR apontam que o trabalho é impactado por desafios estruturais e de relacionamento interpessoal que repercutem em atividades pouco condizentes com a práxis do conceito moderno de promoção da saúde e as diretrizes do Ministério da Saúde para a atuação no NASF, dificultando a edificação de um processo de trabalho conjunto e compartilhado entre as equipes.

Essas dificuldades direcionam a prática do fonoaudiólogo ao saber específico da disciplina e, portanto, ao conhecimento nuclear inerente a cada profissão. A fragmentação da assistência enfraquece o cuidado integral ao usuário e o desenvolvimento de atividades é frágil quando pensado sob a sobreposição dos conceitos de campo e núcleo.

Em síntese, o trabalho do fonoaudiólogo no NASF em municípios paraibanos se revela numa perspectiva nuclear, fazendo-se necessária, para ser efetivo na perspectiva da Saúde Coletiva, a superação de barreiras para que possa ser caracterizado pela interseção entre núcleo e campo.

*LSC foi responsável pela construção teórica, realização e transcrição das entrevistas, análise e discussão dos resultados, redação e metodologia; LMA supervisionou a transcrição das entrevistas, colaborando com a análise e discussão dos resultados e redação do artigo; RSA atuou na apreciação das entrevistas, na análise e discussão dos resultados e redação do artigo; AMCL colaborou na apreciação das entrevistas, na análise e discussão dos resultados, redação e análise crítica; AOS trabalhou na análise e discussão dos resultados, redação e análise crítica; LDS orientou o trabalho do qual o artigo deriva e orientou a construção teórica do artigo, a análise e discussão dos resultados, redação e metodologia.

\section{REFERÊNCIAS}

1. Moreira DR. Fonoaudiologia: sentido produzido por acadêmicos da área da saúde. Estudos. 2006;33(3):397-424.

2. Breilh J. A reprodução social e investigação em saúde coletiva: construção do pensamento e debate. In: Costa DC. Epidemiologia: teoria e objeto. São Paulo: HUCITEC; 1990. p. 137-65.

3. Brasil. Ministério da Saúde. Secretaria de Atenção à Saúde. Departamento de Atenção Básica. Cadernos de Atenção Básica. Diretrizes do NASF Núcleo de Apoio à Saúde da Família. Brasília: Ministério da Saúde; 2010.

4. Campos GWS. Saúde pública e saúde coletiva: campo e núcleo de saberes e práticas. Ciênc Saúde Coletiva. 2000;5(2):219-30.

5. Campos GWS, Amaral MA. A clínica ampliada e compartilhada, a gestão democrática e redes de atenção como referenciais teórico-operacionais para a reforma do hospital. Ciênc Saúde Coletiva. 2007;12(4):849-59.

6. Maldonade IR. Enfrentar a realidade metodologicamente: o Zopp e a organização do trabalho fonoaudiológico por estagiários em UBS. PróFono. 2009;21(2):175-7.
7. Zoboli ELCP, Fortes PAC. Bioética e atenção básica: um perfil dos problemas éticos vividos por enfermeiros e médicos do Programa Saúde da Família, São Paulo, Brasil. Cad Saúde Pública. 2004;20(6):1690-9.

8. Buss PM. Uma introdução ao conceito de promoção da saúde. In: Czeresnia D, Freitas CM, organizadores. Promoção da saúde: conceitos, reflexões, tendências. Rio de Janeiro: Fiocruz; 2003. p. 15-38.

9. Buss PM. Promoção da saúde e qualidade de vida. Ciênc Saúde Coletiva. 2000;5(1):163-77.

10. Lemos M, Bazzo LMF. Formação do fonoaudiólogo no município de Salvador e consolidação do SUS. Ciênc Saúde Coletiva. 2010;15(5):2563-8.

11. Mattos RA. Os sentidos da integralidade: algumas reflexões acerca de valores que merecem ser defendidos. In: Pinheiro R, Mattos RA (org.). Os sentidos da integralidade na atenção e no cuidado em saúde. Rio de Janeiro: CEPESC/IMS/UERJ/ABRASCO; 2001. p. 39-64.

12. Fontanella BJB, Campos CJG, Turato ER. Coleta de dados na pesquisa clínico-qualitativa: uso de entrevistas não-dirigidas de questões abertas por profissionais da saúde. Rev Latino-Am Enfermagem. 2006;14(5):812-20.

13. Orlandi EP. Análise de discurso: princípios e procedimentos. Campinas: Pontes; 2009.

14. Courtine JJ. Definition d'orientations théoriques et construction de procédures en anlyse du discours. Philosophiques. 1982;9(2):239-64.

15. Ginzburg C. Sinais: raízes de um paradigma Indiciário. In: Ginzburg C. Mitos, emblemas, sinais: morfologia e história. São Paulo: Companhia de Letras; 1980. p. 143-80.

16. Bezerra RSS, Carvalho MFS, Silva TPB, Silva FO, Nascimento CMB, Mendonça SS, et al. Arranjo matricial e o desafio da interdisciplinaridade na atenção básica: a experiência do NASF em Camaragibe/PE. Divulg. Saúde Debate. 2010;(46):51-9.

17. Mendes VLF. Inserção da Fonoaudiologia no NASF. Rev Soc Bras Fonoaudiol. 2009;14(1):129-35.

18. Andrade CRF. Fases e níveis de prevenção em fonoaudiologia: ações coletivas e individuais. In: Vieira RM (org.). Fonoaudiologia e saúde coletiva. Carapicuíba: Pró-Fono; 2000. p. 81-104.

19. Mattos RA. A integralidade na prática (ou sobre a prática da integralidade). Cad Saúde Pública. 2004;20(5):1411-6.

20. Peduzzi M. Equipe multiprofissional de saúde: conceito e tipologia. Rev Saúde Pública. 2001;35(1):103-9.

21. Campos GWS, Domiti AC. Apoio matricial e equipe de referência: uma metodologia para gestão do trabalho interdisciplinar em saúde. Cad Saúde Pública. 2007;23(2):399-407.

22. Severo SB, Seminotti N. Integralidade e transdisciplinaridade em equipes multiprofissionais na saúde coletiva. Ciênc Saúde Coletiva. 2010;15(Supp11):1685-98.

23. Ceccim RB, Feuerwerker LCM. O quadrilátero da formação para a área da saúde: ensino, gestão, atenção e controle social. Physis. 2004;14(1):41-65.

24. Molini-Avejonas DR, Mendes VLF, Amato CAH. Fonoaudiologia e Núcleos de Apoio à Saúde da Família: conceitos e referências. Rev Soc Bras Fonoaudiol. 2010;15(3):465-74

25. Panhoca I, Leite APD. A constituição de sujeitos no grupo terapêutico fonoaudiológico-identidade e subjetividade no universo da clínica fonoaudiológica. Distúrb Comun. 2003;15(2):289-308.

26. Bosi MLM, Paim JS. Graduação em Saúde Coletiva: limites e possibilidades como estratégia de formação profissional. Ciênc Saúde Coletiva. 2010;15(4):2029-38. 